\title{
Riproximin: A type II ribosome inactivating protein with anti-neoplastic potential induces IL24/MDA-7 and GADD genes in colorectal cancer cell lines
}

\author{
ASIM PERVAIZ $^{1}$, HASSAN ADWAN ${ }^{1,2}$ and MARTIN R. BERGER ${ }^{1}$ \\ ${ }^{1}$ Toxicology and Chemotherapy Unit, Deutsches Krebsforschungszentrum (DKFZ), D-69120 Heidelberg, Germany
}

Received May 5, 2015; Accepted June 12, 2015

DOI: 10.3892/ijo.2015.3073

\begin{abstract}
Riproximin (Rpx) is a type II ribosome inactivating protein, which was extracted and purified from the seeds of Ximenia americana. Previous studies demonstrated cytotoxicity of Rpx against a variety of cell lines originating from solid and non-solid cancers. In this study, we investigated the mechanistic aspects of Rpx in selected human and rat colorectal cancer (CRC) cell lines. Cytotoxic levels of Rpx were determined by MTT assay, while cytostatic and apoptotic effects were investigated by flow cytometry and nuclear staining procedures. Effects of Rpx exposure on colony formation/migration of CRC cells and expressional modulations in anticancer/stress-related genes were also studied. Rpx showed significant and comparable levels of cytotoxicity in CRC cells as determined by inhibitory concentration (IC) values. Similar inhibitory effects were found for clonogenicity, while more pronounced inhibition of migration was observed in response to Rpx exposure. Profound arrest in $\mathrm{S}$ phases of the cell cycle was noted especially in primary CRC cells. Apoptotic effects were more prominent in rat CRC cells as indicated by Annexin V-FITC assay and Hoechst 33342 nuclear staining. Rpx exposure induced significantly increased levels of the IL24/MDA-7, a well characterized anticancer gene, in all CRC cells. In addition, following Rpx treatment, high expression levels of growth arrest and DNA damage (GADD family) genes were also observed. Increased expression of two additional GADD genes (34 and 153) only in rat CRC cells (CC531) conferred higher sensitivity towards Rpx and subsequent antiproliferative/apoptotic effects as compared to human CRC cells (SW480 and SW620). The present investigation indicates
\end{abstract}

Correspondence to: Professor Martin R. Berger, German Cancer Research Center, Toxicology and Chemotherapy Unit, Im Neuenheimer Feld 581, D-69120 Heidelberg, Germany

E-mail: m.berger@dkfz.de

Present address: ${ }^{2}$ German University of Cairo, Cairo, Egypt

Key words: colorectal cancer cell lines, CC531, SW480, SW620, apoptosis, cell cycle arrest, IL24/MDA-7 gene, GADD genes the anticancer potential of Rpx in CRC and favor further evaluation of this natural compound as therapeutic agent.

\section{Introduction}

Ribosome-inactivating proteins (RIPs) comprise a large family of toxic proteins, which are widely distributed among plants, fungi, algae and bacteria (1-5). Based on their structural properties, RIPs have been divided into three types (I, II and III). Types I and II are the most prevalent forms of RIPs, where type I has a single polypeptide chain, while type II consists of two polypeptide chains (A and B-chains) linked together by a disulfide bond. RIPs inactivate the cellular ribosome machinery by inhibiting the protein translation irreversibly that leads to the death of the respective cells. Toxicity of RIPs is greatly attributed to their RNA N-glycosidase activity, which is responsible for depurination of $28 \mathrm{~S}$ rRNA of eukaryotic ribosomes (6-9). An additional mechanism of action for type II RIP activity has also been identified, which is based on the cellular endoplasmic reticulum (ER) stress (10). Since their discovery and especially in the last ten years, RIPs have drawn a considerable amount of attention as therapeutic agents for the treatment of cancer. In this regard, toxic domains of RIPs are either linked to especially designed molecules (immunotoxins) or delivered directly as cancer gene therapy (11-14).

Ximenia americana, also known as sea lemon or yellow plum, is a small sprawling tree which is widely distributed over the tropical and subtropical areas. Powdered material of this plant has been used in African regions as traditional medicine for the treatment of certain maligant tumors. The active component of $X$. americana, which is a $58-62-\mathrm{kDa}$ protein, was identified and purified almost a decade ago and named 'Riproximin' (Rpx). Based on its amino acid sequence and protein modeling structures, it was placed along with the toxic group of type II RIPs. Closest relatives of Rpx are ricin, viscum lectin I, ebulin and nigrin $b$, which are classical examples of type II RIPs $(15,16)$. Initial in vitro toxicity data revealed the significant antineoplastic potential of Rpx against different cell lines belonging to leukemia and solid tumors. However, this cytotoxicity of Rpx against different cancer cell lines varied over a broad range (maximum by a factor of 100), which is possibly due to differential expression of receptors required for Rpx binding, specific molecular routes and nega- 
tive feedback mechanisms developed by the cancer cells over time. Nevertheless, Rpx illustrated specific toxicity towards tumor cell lines, whereas non-tumor cell lines showed either no or only a marginal sensitivity (16-19). Further investigations on the antineoplastic potential of Rpx were accomplished in colorectal and pancreatic cancer liver metastasis rat animal models. Treatment of both kind of animal models with Rpx (peroral or intraperitoneal) showed a significant reduction in tumor burden as compared to untreated control animals $(20,21)$.

For illuminating the reasons, why gastrointestinal cancer liver metastasis turned out to be a primary target of Rpx activity, we expanded the experiments on metastasis-related aspects of Rpx. For this purpose, we started investigating the effects of Rpx exposure on properties of human and rat colorectal cancer (CRC) cell lines akin to metastasis. While selecting appropriate cell lines, we preferred two human cell lines with primary (SW480) and metastatic (SW620) tumor origin and a primary rat cell line (CC531) to have a comparison of the outcomes in two species for possible extrapolation of experimental results. With regard to biological properties of the cells, we studied the proliferation, colony formation and wound healing assays, which link the steps from tumor growth to metastasis. In addition, we performed the nuclear staining, Annexin V-FITC and cell cycle analysis to assess the possible nuclear/DNA fragmentation and/or cell cycle modulation, respectively. We further aimed at investigating the changes in expressional profiles of genes relevant for apoptosis and mitochondrial/ER-stress in the selected cell lines, to gain insight into the Rpx effects at molecular and mechanistic levels.

\section{Materials and methods}

Cell lines. Two human (SW480 and SW620) and one rat (CC531) colon adenocarcinoma cell lines were cultured and maintained in RPMI-1640 medium (Invitrogen, Darmstadt, Germany) supplemented with L-glutamine $(2 \mathrm{mM})$ and $10 \%$ fetal bovine serum (FBS). The cell lines, free of pathogenic contaminations, were maintained under standard incubation conditions with a humidified atmosphere $\left(5 \% \mathrm{CO}_{2}\right.$, at $\left.37^{\circ} \mathrm{C}\right)$ and passaged routinely to maintain a logarithmically growing cell population.

Cell proliferation assay. Proliferation of the selected cell lines was assessed by MTT (3-[4,5-dimethylthiazol-2-yl]-2,5 diphenyltetrazolium bromide) dye reduction assay. In brief, the cells were seeded $\left(5 \times 10^{3} /\right.$ well) in 96 -well plates and treated with increasing concentrations of Rpx $(1.25-40 \mathrm{ng} / \mathrm{ml})$ for three time periods (24, 48 and $72 \mathrm{~h}$ ). Surviving cell fractions from treated and control groups (8 replicates/sample) were determined by the addition of $10 \mu \mathrm{l} /$ well MTT solution $(10 \mathrm{mg} / \mathrm{ml}$ in PBS). After an incubation period of $3 \mathrm{~h}$ under standard conditions, formazan crystals formed by the viable cells were dissolved with $100 \mu \mathrm{l}$ of acidic 2-propanol $(0.04 \mathrm{~N}$ $\mathrm{HCl})$. Optical density was measured by an ELISA plate reader (Anthos Mikrosysteme GmbH, Krefeld, Germany) at $540 \mathrm{~nm}$ wavelength (690-nm reference filter). Inhibitory concentrations (IC) were determined by GraphPad Prism 6 software and cell survival rates were calculated as the percentage of untreated controls.
Colony formation assay. Following the $\mathrm{Rpx}\left(\mathrm{IC}_{20}\right)$ exposure for $48 \mathrm{~h}, 2 \times 10^{3}$ cells in a semi-liquid medium (0.4\% methylcellulose and 30\% FBS in RPMI-1640 medium) were seeded into 6-well plates. Following the standard incubation conditions for 6-8 days, clusters of cells ( $>10$ cells) were counted by an inverted microscope (Leitz Fluovert FU Microscope, Wetzlar, Germany) and grouped into small ( $<30$ cells) or large ( $\geq 30$ cells) colonies. Furthermore, the colonies were fixed with a solution of methanol and acetic acid (3:1 ratio respectively) and stained with $0.5 \%$ crystal violet (in methanol). Data were represented as percentage of the colonies formed by the untreated control cells.

Wound healing assay. The cells were seeded at optimized cell density ( $2 \times 10^{5}$ SW480 and SW620, 1.25x10 CC531 cells) in 12-well plates and were allowed to grow for $24 \mathrm{~h}$ under standard conditions. Monolayers of the confluent cells were scratched in a straight line by a $200-\mu 1$ sterile yellow tip and free-floating cells were removed. Opti-MEM ${ }^{\circledR} \mathrm{I}$ serum reduced medium (Invitrogen) was added and then the cells were exposed to the Rpx $\left(\mathrm{IC}_{20}\right)$. Effect on 'wound closing' by the cells was observed and photographed at zero and $24 \mathrm{~h}$ by an Axio Observer Z1 microscope (Carl Zeiss, Oberkochen, Germany). Three random photographs were taken per sample for each time-point.

Cell cycle assay. Effects of Rpx treatment on cell cycle were determined by propidium iodide (PI) fluorescent staining and flow cytometry analysis (FACS). Briefly, the cells were exposed to $\mathrm{Rpx}\left(\mathrm{IC}_{25}, \mathrm{IC}_{50}\right.$ or $\left.\mathrm{IC}_{75}\right)$ for $48 \mathrm{~h}$, harvested and washed with PBS followed by the addition of ice cold ethanol (70\%) to fix and permeabilize the cells. After an incubation period of $2 \mathrm{~h}$ at $4^{\circ} \mathrm{C}$, the cells were washed again and re-suspended in PBS having RNaseA $(1 \mathrm{mg} / \mathrm{ml})$ and incubated for $30 \mathrm{~min}$ at $37^{\circ} \mathrm{C}$. PI $(50 \mu \mathrm{g} / \mathrm{ml})$ was added to the cells and analysis was done immediately ( $\leq 30 \mathrm{~min})$ in a FACSCanto (BD Biosciences, San Jose, CA, USA). Ten thousand cells (events) from each sample were analyzed and distribution of the cells in G0/G1, $\mathrm{S}$ and G2/M phases of cell cycle was calculated by ModFit LT software. In addition, apoptotic cell fractions were determined by sub-G1 peak from the DNA histogram using FACSDiva software (BD Biosciences).

Nuclear staining. The cells were seeded in 6-well plates having sterilized cover slips inside and treated with $\mathrm{Rpx}\left(\mathrm{IC}_{25}\right.$, $\mathrm{IC}_{50}$ or $\mathrm{IC}_{75}$ ) for $48 \mathrm{~h}$. Later on, the cells were washed with PBS, fixed with $4 \%$ formaldehyde and permeablized with $0.3 \%$ Tritron X-100 (Sigma, Munich, Germany). The cells were stained with $1.6 \mathrm{mM}$ Hoechst 33342 dye (Invitrogen, Karlsruhe, Germany), spun on glass slides and were systematically photographed at random areas with an Axiophot microscope (Carl Zeiss).

Annexin V-FITC binding assay. Apoptotic response of the cells to Rpx treatment was investigated by Annexin V-FITC apoptosis detection kit (eBioscience, Frankfurt, Germany). In brief, the cells were treated with $\mathrm{Rpx}\left(\mathrm{IC}_{25}, \mathrm{IC}_{50}\right.$ or $\left.\mathrm{IC}_{75}\right)$ for $48 \mathrm{~h}$ and harvested with EDTA free trypsin. After the two washing steps (PBS and $1 \mathrm{X}$ binding buffer), the cells $\left(2 \times 10^{5}\right)$ were resuspended in $100 \mu \mathrm{l}$ of $1 \mathrm{X}$ binding buffer (provided by 
Table I. Primers for selected genes.

\begin{tabular}{|c|c|c|c|c|}
\hline Genes & Forward primer & Reverse primer & Probe no. ${ }^{\mathrm{a}}$ & Probe ID $^{\mathrm{a}}$ \\
\hline \multicolumn{5}{|l|}{ Human } \\
\hline IL24/MDA-7 & cccagaaactgtgggaagc & gggcactcgtgatgttatcc & 26 & 04687574001 \\
\hline GADD45A & ggagagcagaagaccgaaag & agtgatcgtgcgetgactc & 37 & 04687957001 \\
\hline GADD45B & cattgtctcctggtcacgaa & taggggacccactggttgt & 10 & 04685091001 \\
\hline GADD45G & cagccaaagtcttgaacgtg & cctggatcagcgtaaaatgg & 71 & 04688945001 \\
\hline GAPDH & agccacatcgctcagacac & gcccaatacgaccaaatcc & 60 & 04688945001 \\
\hline \multicolumn{5}{|l|}{ Rat } \\
\hline IL24/MDA-7 & gctgttgaaaccacaggttct & ttgaatttgactattttgctgtgat & 40 & 04687990001 \\
\hline GADD45A & cagagcagaagatcgaaagga & gactccgagccttgctga & 65 & 04688643001 \\
\hline GADD45B & ctgcctcctggtcacgaa & ttgcctctgctctcttcaca & 10 & 04685091001 \\
\hline GADD45G & gtccgccaaagtcctgaat & tcgecetcatcttcttcgt & 71 & 04688945001 \\
\hline GADD34 & tcctctgaagggtagaaaggtg & cttcgatctcgtgcaaactg & 26 & 04687574001 \\
\hline GADD153 & accaccacacctgaaagca & agctggacactgtctcaaagg & 13 & 04685121001 \\
\hline G-tubulin & tctacaacccagagaacatctacct & tgatgtcaaaaatgtcetcgtg & 25 & 04686993001 \\
\hline
\end{tabular}

${ }^{\mathrm{a} U n i v e r s a l ~ p r o b e ~ l i b r a r y . ~}$

the kit) and $5 \mu \mathrm{l}$ of fluorochrome-conjugated Annexin V-FITC was added, followed by $15-\mathrm{min}$ incubation at room temperature in the dark. Cells were washed with $1 \mathrm{X}$ binding buffer to remove additional unbound Annexin V-FITC and resuspended in $200 \mu \mathrm{l}$ of $1 \mathrm{X}$ binding buffer. PI $(5 \mu \mathrm{l})$ was added to each sample and analyses were done with a FACS Calibur flow cytometer (BD Biosciences).

RNA isolation and cDNA synthesis. The cells were seeded in 6-well plates and treated with increasing concentrations of $\mathrm{Rpx}\left(\mathrm{IC}_{25}, \mathrm{IC}_{50}\right.$ or $\left.\mathrm{IC}_{75}\right)$ the next day. After $48 \mathrm{~h}$ of exposure time, the cells were harvested, washed and total RNA was extracted from the cell pellets with RNeasy Mini kit (Qiagen, Hilden, Germany) following the manufacturer's protocol. Concentrations of the isolated RNA were measured by a GeneQuant pro spectrophotometer (GE Healthcare, Munich, Germany) and complementary DNA (cDNA) was synthesized by Maxima reverse transcriptase enzyme (Thermo Scientific, Schwerte, Germany).

Real-time qPCR. Effects of Rpx exposure on expression profile of apoptosis relevant genes (IL24/MDA-7 and GADD family) were studied by qRT-PCR methodology. For this purpose, prepared cDNA $(1 \mu \mathrm{g})$ from the control and treated samples was subjected to PCR amplification procedure by using 2X LC480 master mix along with an appropriate probe from the Universal probe library (Roche, Mannheim, Germany). Samples were processed in triplicate and the expression level of glyceraldehyde 3-phosphate dehydrogenase (GAPDH) and gamma-tubulin (G-tubulin) were used for normalization of the data. The fold-changes in the expression levels were calculated by the $2^{-\triangle \Delta C T}$ method (22). Primer sequences used for the amplifications of selected genes are given in Table I.

Statistical analysis. GraphPad Prism 6 software was used for the statistical analysis of the data. All the data are represented as mean \pm standard deviation (SD). A $\mathrm{P}<0.05$ was selected as significant to interpret statistical significance of the results.

\section{Results}

Rpx induces antiproliferative effects in CRC cells. Cells from selected CRC cell lines were treated with increasing concentrations of purified Rpx (1.25-40 ng/ml) for 24, 48 and $72 \mathrm{~h}$, and antiproliferative effects were evaluated by MTT dye-reduction assay. An effective antiproliferative activity was observed as survival rates, following Rpx exposure, declined in a concentration and time-dependent format in the exposed cells. At low Rpx concentrations ( $\leq 5 \mathrm{ng} / \mathrm{ml})$, a steep inhibition in survival rate was found, especially following the 48 and $72 \mathrm{~h}$ exposure periods in dose-response curves as shown in Fig. 1. The relevant concentrations $\left(\mathrm{IC}_{20}-\mathrm{IC}_{75}\right)$ were calculated based on this viability assay and applied in all subsequent experimental procedures.

Inhibition of colony formation by Rpx exposure. Colony formation assay was used to monitor the effects of Rpx on colony forming ability of single tumor cells. For this purpose, the cells were exposed to the respective $\mathrm{IC}_{20}$ of $\mathrm{Rpx}$ and colony forming units ( $\mathrm{CFU}>10$ cells) were counted 6-8 days later. In the untreated control cells, totals of 421, 438 and 219 colonies (small and large) were identified, which corresponded to ratios of 21, 22 and 11\% CFU for SW480, SW620 and CC531 cells, respectively. Rpx exposure reduced this ability to produce small colonies by $32(\mathrm{P}=0.0075), 27(\mathrm{P}=0.0032)$ and $23 \%(\mathrm{P}=0.0063)$ in SW480, SW620 and CC531 cells, respectively. Rpx treatment was more effective in inhibiting the formation of large colonies in CC531 cells (43\%, $\mathrm{P}=0.0040)$, as compared to SW480 (18\%, $\mathrm{P}=0.0823)$ and SW620 (24\%, $\mathrm{P}=0.0463)$ cells, respectively.

Rpx treatment interrupts the wound healing process. The cells from the three CRC cell lines were subjected to the "wound 

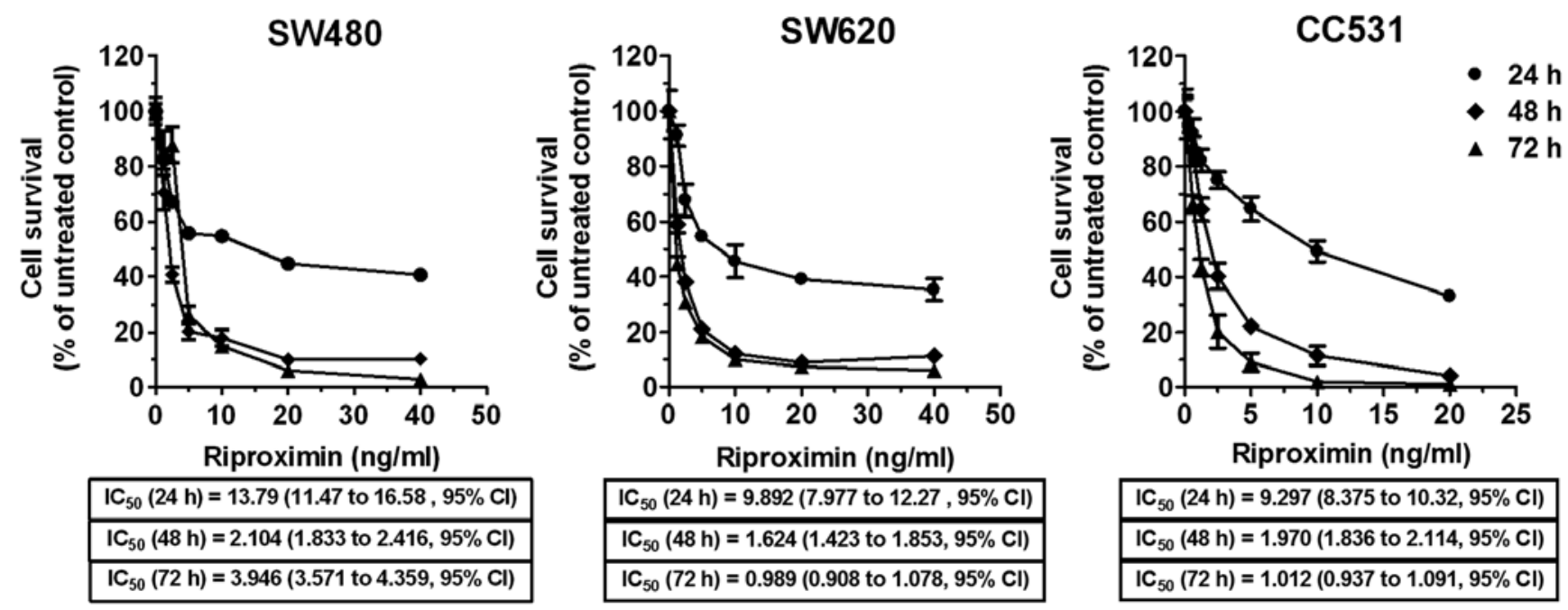

Figure 1. In vitro cytotoxic effects of riproximin in colorectal cancer cells. SW480, SW620 and CC531 cells were treated with riproximin for 24,48 and $72 \mathrm{~h}$. Cytotoxicity was measured by MTT dye reduction assay, corresponding $\mathrm{IC}_{50}$ values with $95 \%$ confidence limits are provided below the respective curves.
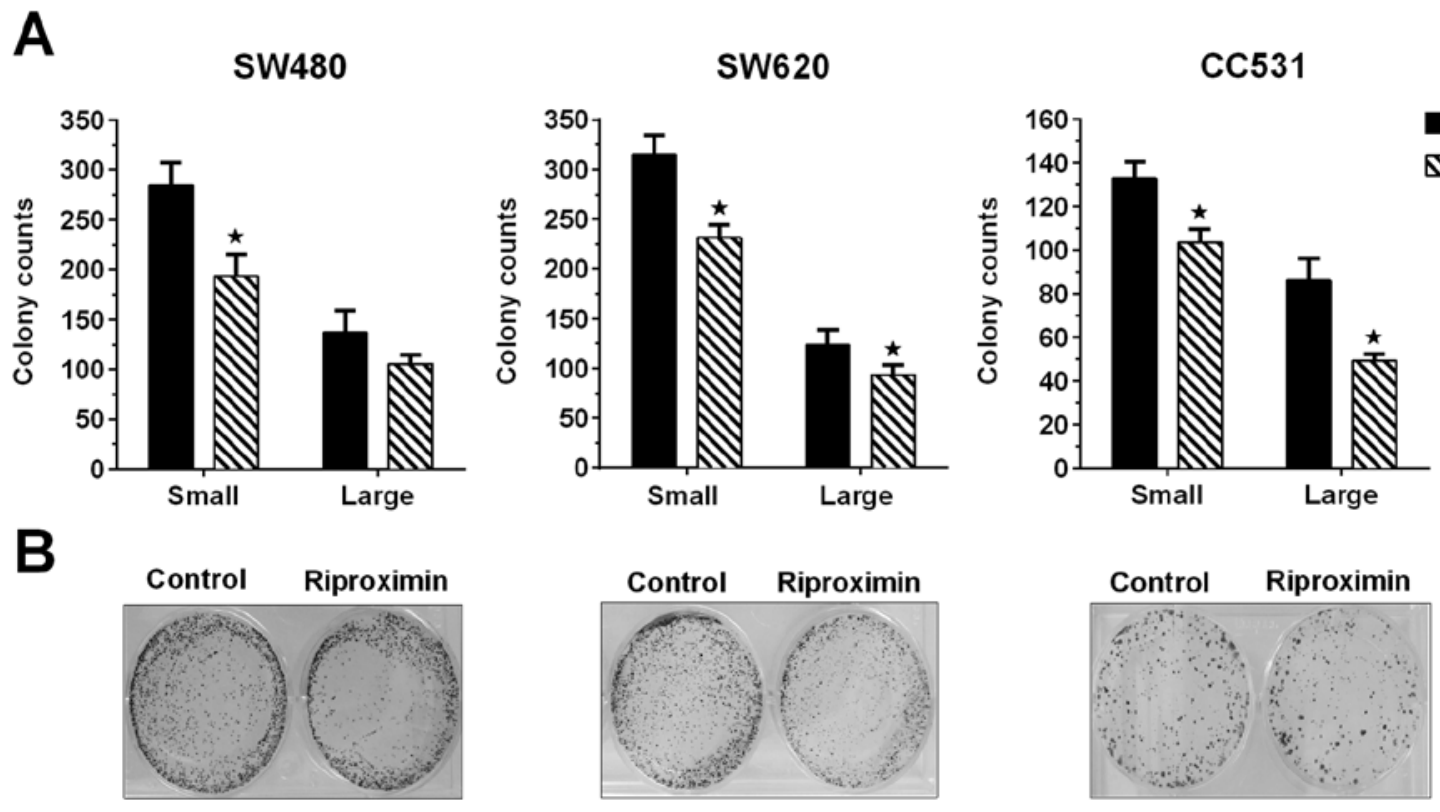

Figure 2. Effects of riproximin on clonogenicity. Exposure to low concentrations of riproximin moderately inhibited the colony formation in rat and human colorectal cancer cells. An asterisk denotes significant difference $(\mathrm{P}<0.05)$ between control and treated cells.

healing' assay and concomitantly exposed to $\mathrm{Rpx}\left(\mathrm{IC}_{20}\right)$. The ability of cells to cover the scratched area was followed for $24 \mathrm{~h}$. The cell lines, following Rpx exposure, showed significant reduction in their ability to fill the area between the scratched edges. CC531 control cells covered almost the complete area between the scratched edges $(477 \pm 9 \mu \mathrm{m})$, whereas Rpx exposure inhibited this potential by $69 \%(147 \pm 9 \mu \mathrm{m})$. For the human CRC cell lines, wound healing response was recorded as number of migratory cells between the scratched areas. Following Rpx treatment, the effects were more profound in SW480 cells with $75 \%$ inhibition of migratory potential of cells as compared to SW620 cells, where maximum reduction was $67 \%$. The differences in the control and treated groups were statistically significant $(\mathrm{P}<0.05)$ for all cell lines as shown in Fig. 3.
Rpx stimulated the arrest in $S$ phase of the cell cycle. Comparison of the two human CRC cell lines (SW480 and SW620) illustrated a similar cell cycle distribution with relatively high and balanced ratios of G0/G1 (43-46\%) and $\mathrm{S}$ phase $(51 \%)$ cells, while the respective proportions of cells in $\mathrm{G} 2 / \mathrm{M}$ phase were remarkably low (3-6\%). In contrast, the rat cell line (CC531) was characterized by preponderance of G0/G1 phase cells (58\%) and a relative equal distribution of $\mathrm{S}$ (20\%) and G2/M phase cells (22\%). Following Rpx exposure $\left(\mathrm{IC}_{25}, \mathrm{IC}_{50}\right.$ or $\mathrm{IC}_{75}$ ) for $48 \mathrm{~h}, \mathrm{FACS}$ analysis showed significant alterations in cell cycle distributions of all three cell lines. Rpx induced a noteworthy arrest in the $\mathrm{S}$ phase of the cell cycle, as indicated by a steady increase in the cell percentages in this phase. This phenomenon was persistent for all cell lines in a concentration-dependent format, where G0/G1 cells 
A

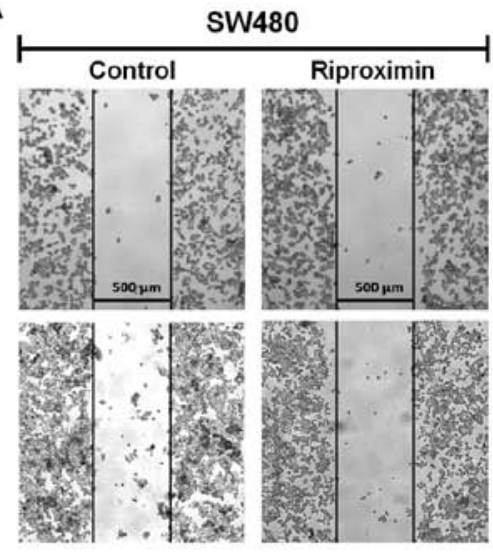

B

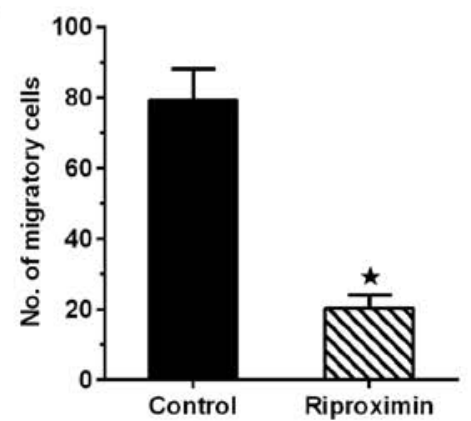

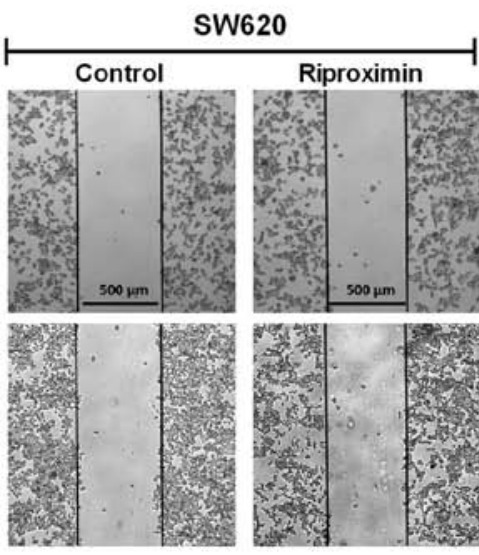
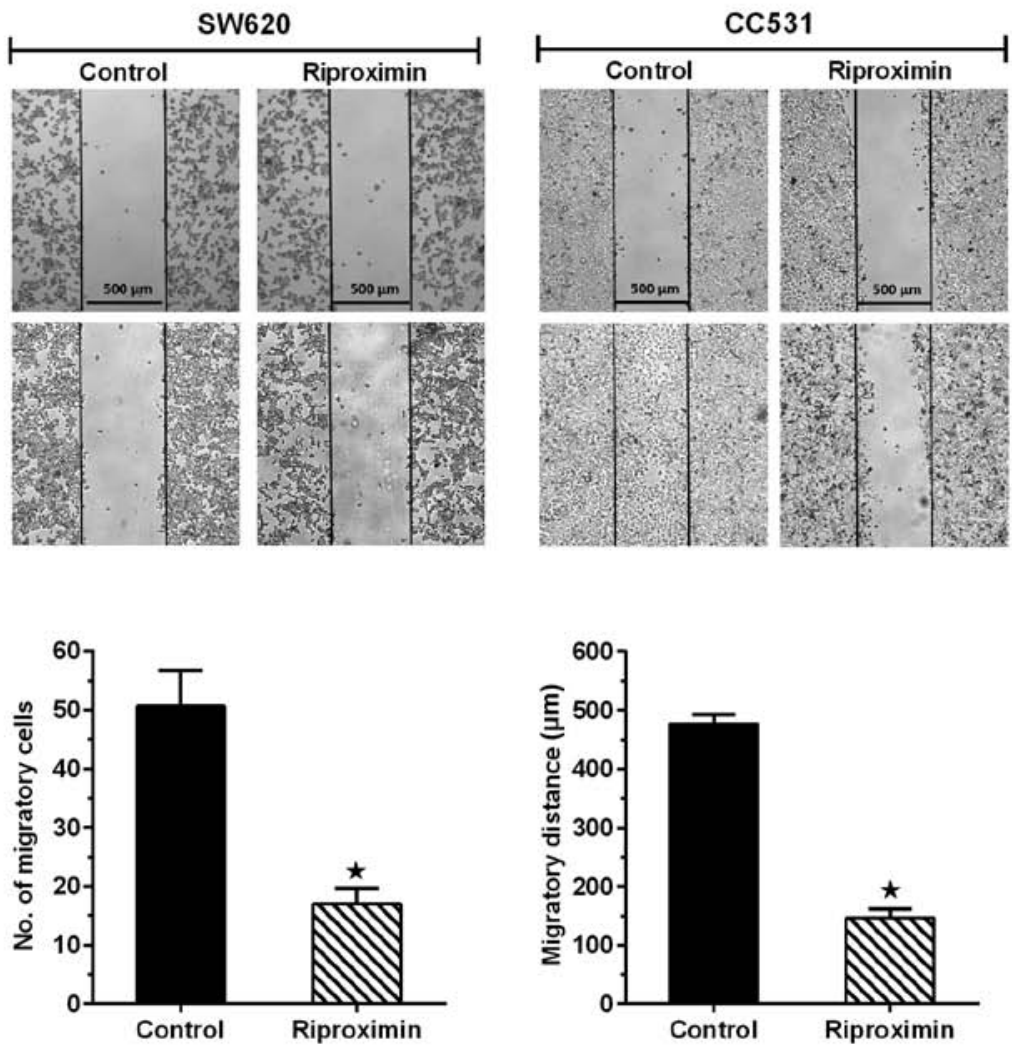

Figure 3. Inhibition of migration by riproximin. Treatment with riproximin $(24 \mathrm{~h})$ significantly inhibited the migratory behavior of colorectal cancer cells. The antimigratory effects were found in all human and rat colorectal cancer cells. The asterisk denotes significant difference $(\mathrm{P}<0.05)$ between control and treated cells.

dropped by maximally 15,8 and $14 \%$ for SW480, SW620 and CC531 cells, respectively. This loss was subsequently gained in S phase, where the maximum increases were 15, 7 and $15 \%$ for SW480, SW620 and CC531 cells, respectively. The G2/M phase remained almost unaltered with the respective percentages reflecting the significant differences between untreated cells (Fig. 4).

Induction of nuclear fragmentation. For determining the ability of Rpx to induce apoptotic effects, we studied the nuclear morphology by Hoechst 33342 staining in the selected cell lines. For this purpose, the cells were exposed to increasing concentrations of Rpx $\left(\mathrm{IC}_{25}, \mathrm{IC}_{50}\right.$ or $\mathrm{IC}_{75}$ ) and resulting effects were monitored after $48 \mathrm{~h}$ of treatment. Rpx induced destructive changes in the nuclei of all three cell lines concentration-dependently. The effects were exerted even at lower concentrations $\left(\mathrm{IC}_{25}\right)$, where chromatin condensation and nuclear shrinkage were observed. At higher Rpx concentrations $\left(\mathrm{IC}_{50}\right.$ or $\left.\mathrm{IC}_{75}\right)$, nuclear/DNA fragmentation was also noted in the cell lines. These apoptotic effects are reflected by the sub-G1 fractions of the three cell lines obtained by flow cytometry (Fig. 5).

Rpx as a stimulus of apoptosis. To validate the ability of $\mathrm{Rpx}$ as an apoptosis inducer, which we observed initially by Hoechst 33342 staining, Annexin V-FITC based assay was performed in the selected cell lines. The cells were exposed to $\mathrm{Rpx}\left(\mathrm{IC}_{25}, \mathrm{IC}_{50}\right.$ or $\mathrm{IC}_{75}$ ) for $48 \mathrm{~h}$, labeled with Annexin V-FITC and examined by FACS analysis. A significant increase in Annexin V-FITC-positive cells (7-22\%) was observed in response to the increasing concentrations of Rpx, as shown in Fig. 6. This steady increase in the percentage of Annexin V-FITC bound cells concentration-dependently corroborated our cytotoxicity and DNA/nuclear fragmentation data from MTT and nuclear staining assays, respectively.

Rpx mediates induction of apoptosis/ER-stress relevant genes. The observed apoptotic processes such as fragmentation of nuclei/DNA and high percentages of Annexin V-positive cells after Rpx treatment provoked us to study the expression profiles of apoptosis/ER-stress-related genes. In this regard, we selected a gene with anticancer potential (IL24/MDA-7) and its downstream targets (GADD genes). The cells were treated with Rpx $\left(\mathrm{IC}_{25}, \mathrm{IC}_{50}\right.$ or $\left.\mathrm{IC}_{75}\right)$ for $48 \mathrm{~h}$ and the expression profiles of the selected genes were studied by qRT-PCR technology. These experiments illustrated a significant potential of Rpx to induce IL24/MDA-7 and GADD family genes in the cell lines (Fig. 7). In SW480 cells, we observed a maximum induction of 6.9-, 7.3-, 3.2- and 12-fold for IL24/MDA-7, GADD45 A, B and $\mathrm{G}$ genes, respectively. These effects followed a concentration-dependent format for GADD45 B and G, whereas IL24/ MDA-7 and GADD45A genes were induced maximally by $\mathrm{IC}_{25}$ and $\mathrm{IC}_{50}$ concentrations, respectively. For SW620, the induction of all selected genes was steady in response to Rpx concentrations, where maximum induction was 2.8-, 4.2-, 8.2and 32.7-fold for IL24/MDA-7, GADD45 A, B and G genes, respectively. Interestingly, we did not find any expression of GADD34 and 153 genes in our control or treated human CRC cell lines. In CC531 cells, the response was mixed, where 
A
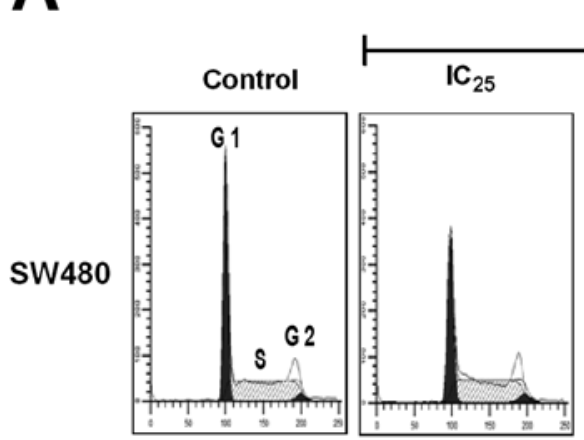

Riproximin
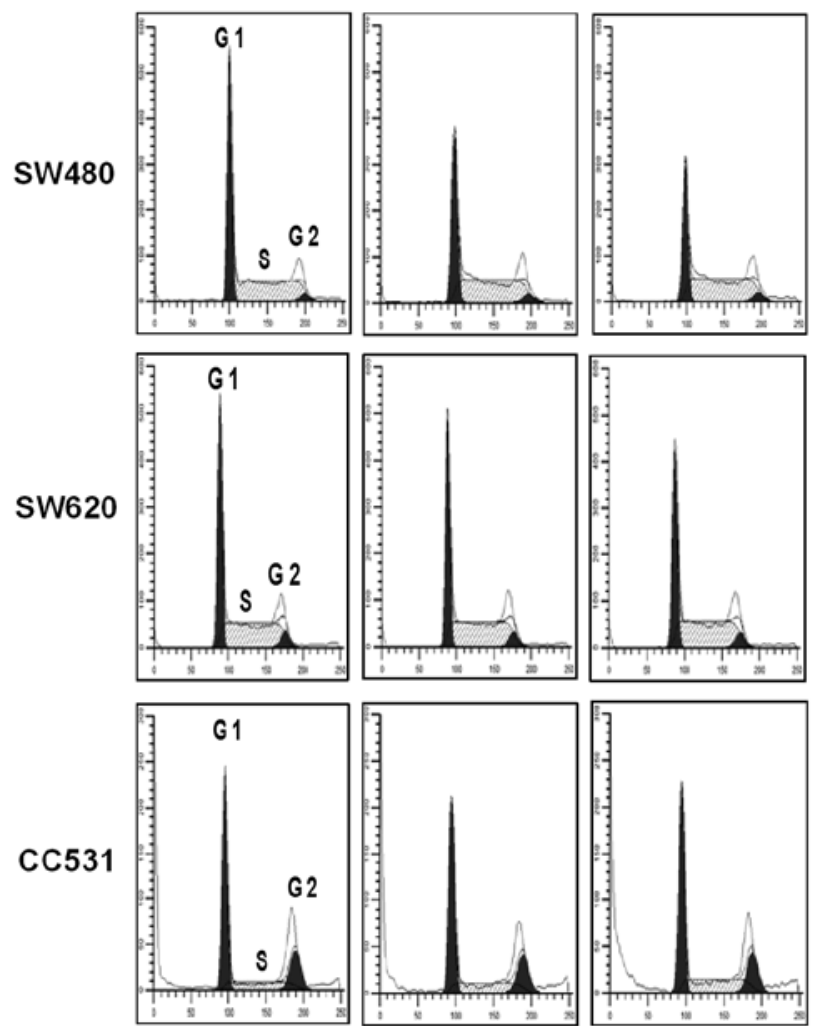

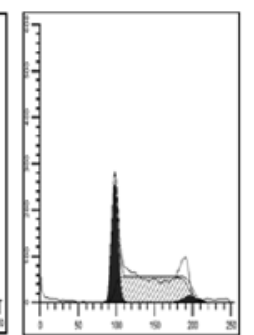

- Control $\Phi \mathrm{IC}_{25} \otimes \mathrm{IC}_{50} \otimes \mathrm{IC}_{75}$
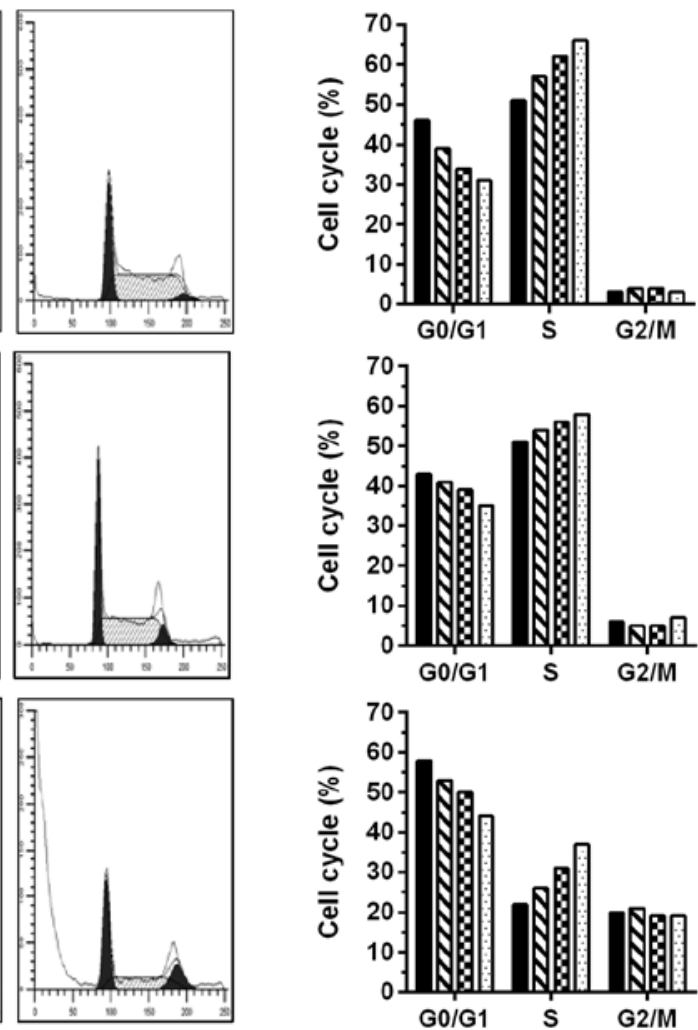

Figure 4. Effects of riproximin ( $48 \mathrm{~h}$ ) on the cell cycle. (A) Riproximin induced significant arrest in $\mathrm{S}$ phases of the cell cycle in colorectal cancer cells (B) Relevant cell fractions (\%), from the three phases of the cell cycle, are given.
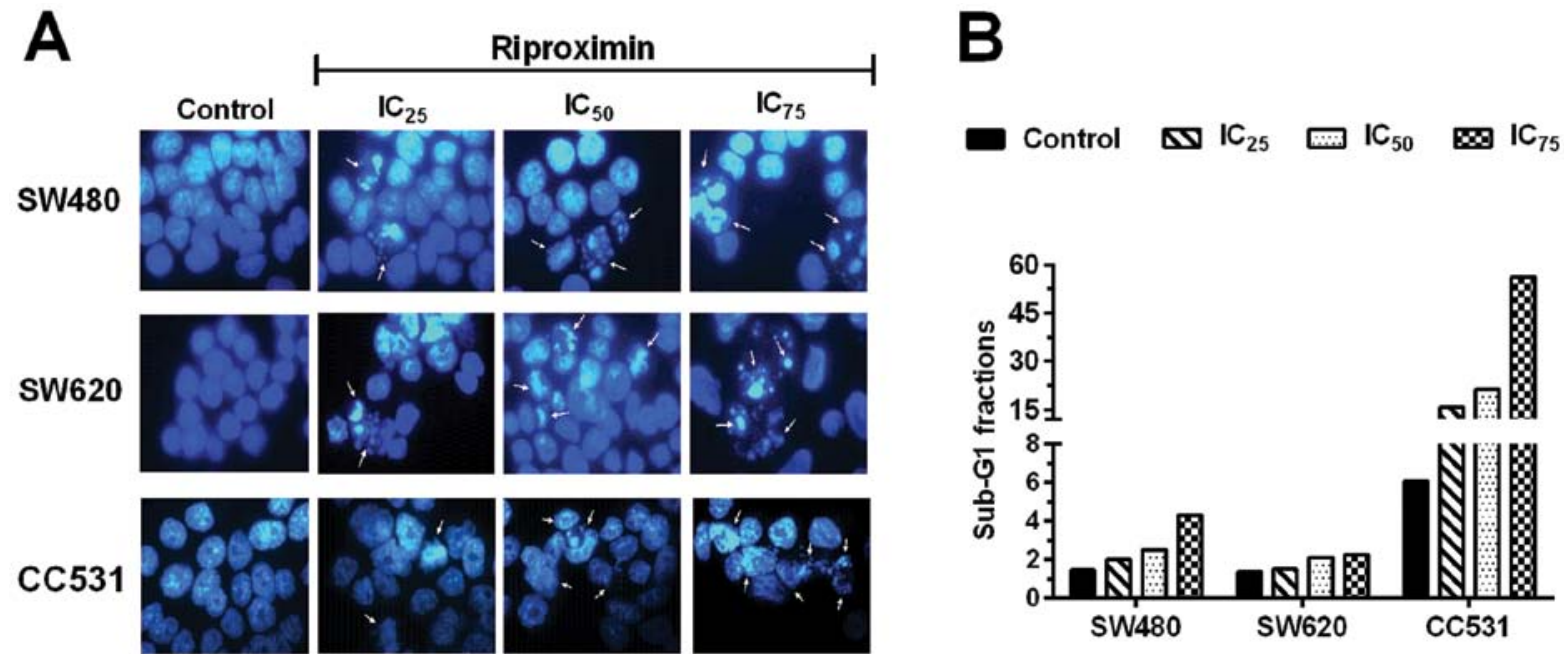

Figure 5. Morphological signs of apoptosis induced by riproximin $(48 \mathrm{~h})$ in colorectal cancer cells. (A) Riproximin induced significant nuclear shrinkage, chromatin condensation and fragmentation in colorectal cancer cells as indicated by the arrows. (B) After the exposure with riproximin, sub-G1 (hypodiploid) DNA fractions were obtained from flow cytometry analysis.

IL24/MDA-7 followed a linear increase with a maximum induction of 3-fold, while GADD45A was downregulated to a moderate level (maximum -1.3-fold). Significant induction was observed for the other GADD genes in CC531 cells, where the maximum-fold change was 5.7-, 6.7-, 5.7- and 3.7-fold for GADD 45B, 45G, 34 and 153, respectively.

\section{Discussion}

The high cytotoxic potential of Rpx in diverse types of cancer cells and its ability to effectively reduce tumor burden in colorectal and pancreatic liver metastasis rat models were studied previously $(20,21)$. With regard to CRC, rat cancer cells 


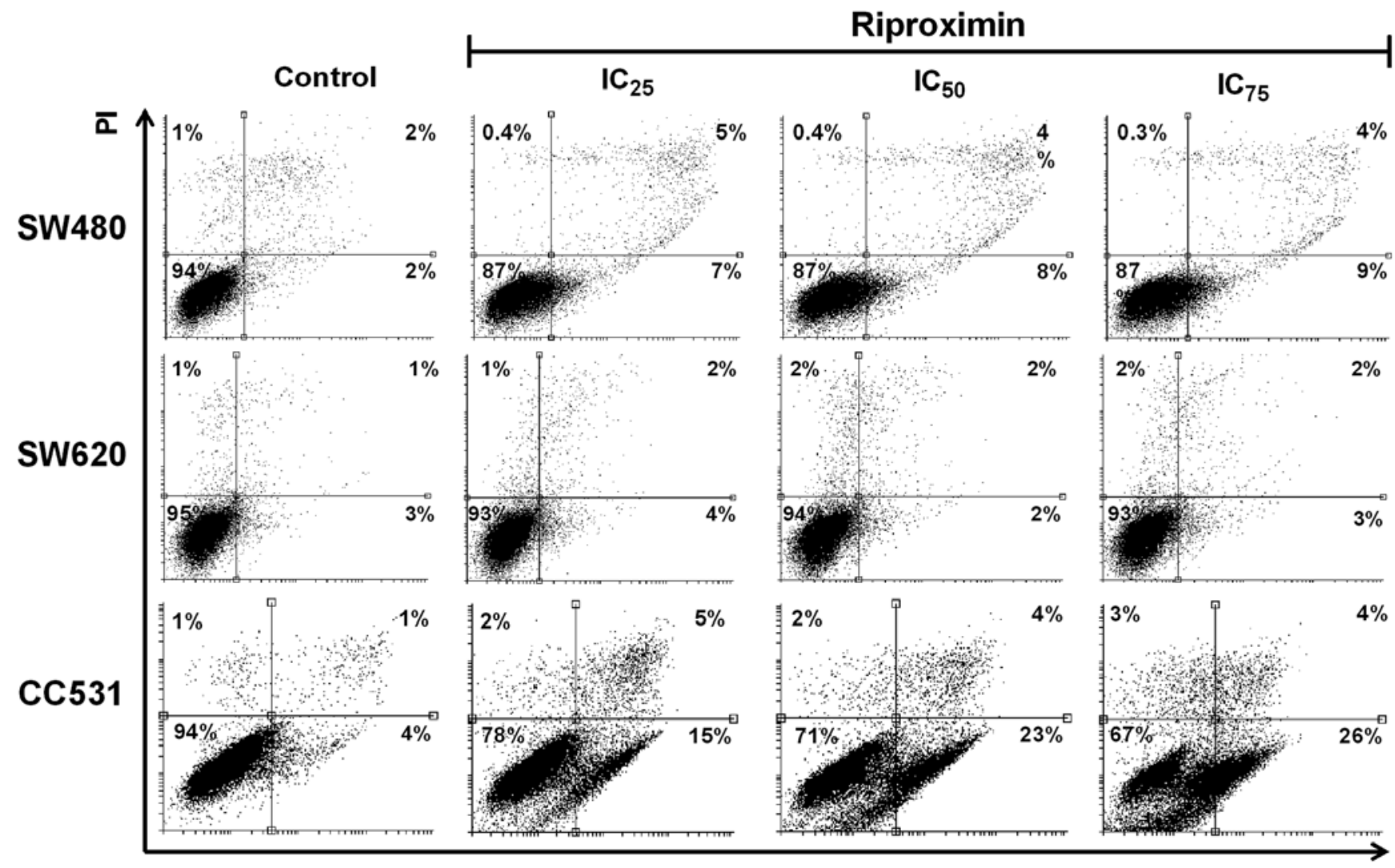

Annexin V-FITC

Figure 6. Apoptotic effects of riproximin $(48 \mathrm{~h})$ on colorectal cancer cells. Induction of apoptosis in colorectal cancer cells by riproximin exposure was determined by Annexin V-FITC assay. Riproximin induced early signs of apoptosis concentration-dependently in primary colorectal cancer cells (SW480 and CC531).

A

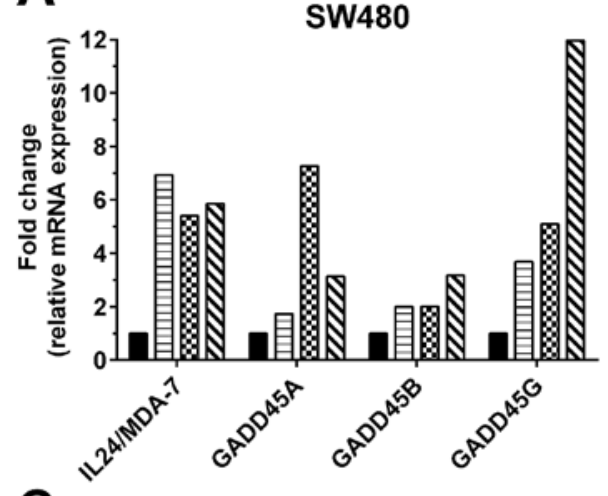

C

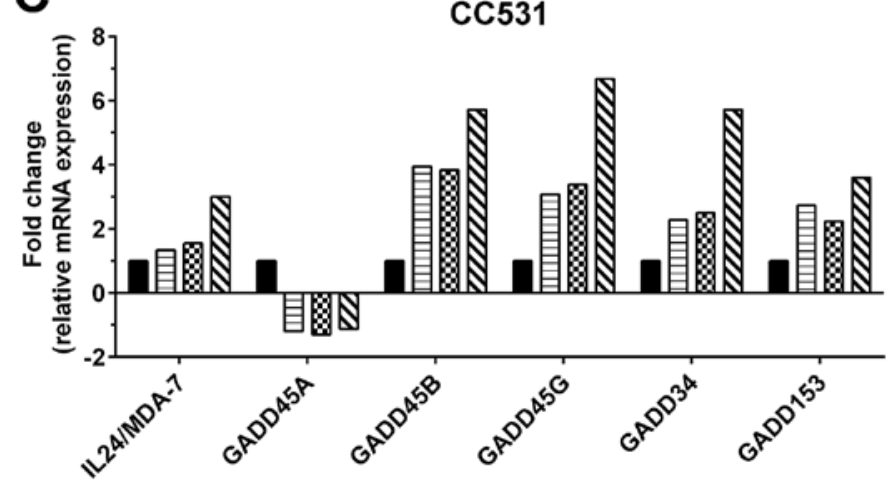

B

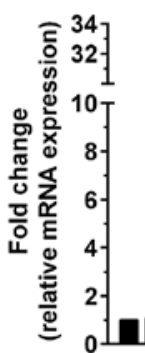

SW620

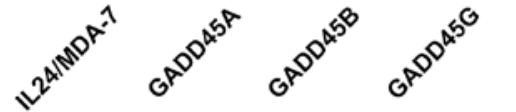

Control

目 $I_{25}$

$\otimes \mathrm{IC}_{50}$

$\mathbf{N} \mathrm{IC}_{75}$

Figure 7. Induction of apoptosis and ER-stress-related genes by riproximin exposure. (A and B) Riproximin induced expression of IL24/MDA-7 and its downstream targets GADD45 A, B and G genes in human colorectal cancer cells. (C) In rat colorectal cancer cells, additional expression of GADD34 and 153 genes was also found along with GADD45 B, G and IL24/MDA-7 genes. 
Riproximin

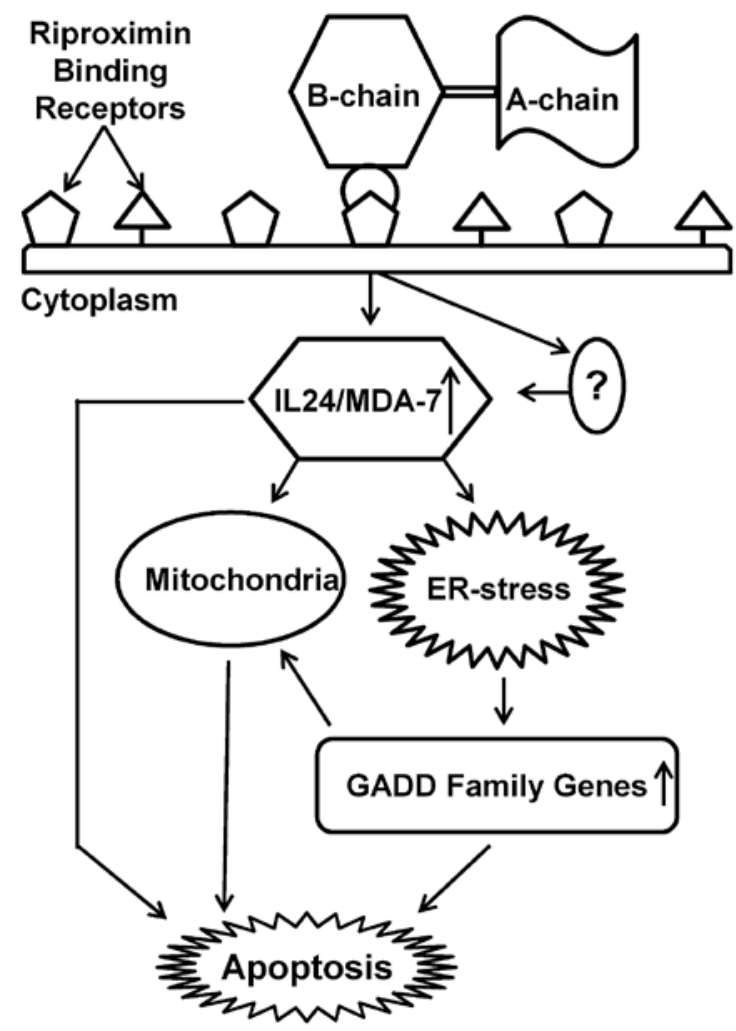

Figure 8. Riproximin mediated signaling pathway. Based on the published literature and our findings in this study, we postulate a riproximin mediated signaling cascade, leading to apoptosis in colorectal cancer cells.

(CC531) were found to be highly sensitive to Rpx exposure (16). In a subsequent report, HCT116 CRC cells were also found sensitive to Rpx (10). Based on these promising results, we incorporated another two human CRC cell lines (SW480 and SW620) and determined the cytotoxic levels of Rpx by MTT dye reduction assay. Considering the $\mathrm{IC}_{50}$ values $(\mathrm{ng} / \mathrm{ml})$ for $48 \mathrm{~h}, \mathrm{Rpx}$ showed comparable cytotoxicity in the three selected $\mathrm{CRC}$ cell lines and indicated high anticancer potential in our previous studies in vivo $(17,21)$. All CRC cells demonstrated a steep decline at low Rpx concentrations $(\leq 5 \mathrm{ng} / \mathrm{ml})$, while the effects were not steady in proportion to further increasing Rpx concentrations. In line with this, despite the similar $\mathrm{IC}_{50}$ values at $48 \mathrm{~h}$, the human CRC cells showed some degree of resistance at higher Rpx concentrations ( $\geq 20 \mathrm{ng} / \mathrm{ml})$.

Compared to the anti-proliferative effects, Rpx caused similar in ratio anti-clonogenic effects, but a 3-4-fold increased inhibition of migration. These profound anti-migratory effects, observed by scratch assay, were significant regardless of the primary or metastatic nature of CRC cells. A high potential of Rpx, as an anti-migratory agent for CRC cells, illustrates its ability to reduce the risk of tumor cell migration and its possible metastasis. Different study reports have confirmed the potential of RIPs to inhibit colony formation as well as migration of cancer cells (23-29). To clarify the reasoning behind anti-proliferative effects, observed by MTT assay, we investigated the impact of Rpx exposure on cell cycle and apoptosis relevant activities of CRC cells. Many studies have described the potential of RIPs as cytostatic agents for cancer cells $(29,30)$, where they imposed arrest in different stages of the cell cycle (G0/G1, S or G2/M). In our study, Rpx induced profound cytostatic effects at the transition from $\mathrm{S}$ to $\mathrm{G} 2$ phases, thus high proportions of these cells were arrested in a dose-dependent manner in the $\mathrm{S}$ phase of the cell cycle. These cytostatic effects were more prominent in primary CRC cells (SW480 and CC531) than in cells of the metastatic line (SW620).

A vast majority of reports have illustrated the potential of RIPs to exert apoptotic effects in cancer cells (31-34). Keeping in view this fact, we aimed at finding the possible apoptotic effects of Rpx in selected CRC cells. Following Rpx exposure, we observed apoptotic effects at morphological levels, which included blebbing, shrinkage and detachment of CRC cells from the culture plates. Furthermore, we also examined condensation and fragmentation of nuclear contents of CRC cells concentration-dependently. Rpx mediated apoptotic effects were further accomplished and confirmed by Annexin V-FITC assay. Remarkably, these apoptotic effects, observed by nuclear staining and Annexin V-FITC assays, were higher in rat than human CRC cells. As these results paralleled the anti-proliferative effects, we concentrated on factors which might have contributed to these differences.

In our previous study (10), we confirmed that Rpx induced the unfolded protein response (UPR), resulting in endoplasmic reticulum (ER) stress of cancer cells and apoptosis. In the same study, we also identified a marked upregulation of the IL24/MDA-7 expression in MDA-MB-231 breast cancer cells. In this study, we investigated a possible expressional modulation of the IL24/MDA-7 gene and its downstream targets in CRC cells. Following Rpx exposure, we observed significantly increased mRNA levels of the IL24/MDA-7 gene ( $\geq 2$-fold). The IL24/MDA-7 gene has been grouped with highly effective anticancer genes (35) and exerts tumor suppressor effects in a variety of solid and non-solid cancers (36-39). With clinical perspective, low levels of the IL24/MDA-7 have been observed in cancerous conditions including CRC. Consequently, these low levels of the IL24/MDA-7 have been associated with poor prognosis, shorter disease-free survival and metastasis (40-42). In order to maintain high levels of this protein, recombinant IL24/MDA-7 has been implicated in clinical trials for treatment of various solid tumors. At the same time, efforts are being carried out to find novel reagents, which can induce the expression of the IL24/MDA-7 in cancerous conditions $(43,44)$. Taking into consideration the anticancer properties of the IL24/MDA-7, the ability of Rpx to induce this gene in CRC cells seems to be of paramount importance. With reference to the downstream signaling factors of the IL24/MDA-7 gene, we focused on growth arrest and DNA damage (GADD family) genes in this study. The IL24/MDA-7 gene has been shown to induce the expression of GADD genes by means of the p38 MAPK pathway (45). GADD genes are stress-related genes, which play an important role in apoptosis and transcriptional regulation of various pro- and/or anti-apoptosis genes (46). In this study, we found the induction of three members of the GADD family genes (A, B and G) in response to Rpx exposure in human CRC cells. In rat CRC cells, in addition to GADD B and $\mathrm{G}$, we also observed significant induction ( $\geq 2$-fold) of two additional GADD genes (GADD34 and 153). These additional GADD genes have been reported to induce the production of reactive oxygen species (ROS), high levels of ceramides and 
inhibition of anti-apoptotic genes like BCL-2 $(47,48)$. Thus, induction of GADD34 and 153 was possibly responsible for the more profound anti-proliferative and apoptotic effects in rat CRC cells as observed by MTT assay, nuclear staining and Annexin V-FITC based protocols in this study. This confirms Rpx induced, previously reported UPR/ER-stress and also demonstrates the possible involvement of the mitochondrial arm of apoptosis in certain cancer cell lines. Based on our observations and the above cited literature, we postulate a Rpx mediated pathway with the involvement of IL24/MDA-7 and GADD genes as shown in Fig. 8, which has bearing for both, the ER and mitochondrial pathways leading to apoptosis.

In conclusion, Rpx exerts significant anti-migratory, cytostatic and apoptotic effects in CRC cells. These anti-neoplastic effects were found in both, primary and metastatic CRC cell lines. In addition, the ability of Rpx to induce the anticancer gene IL24/MDA-7 and ER-stress via GADD induction highlights the therapeutic potential of this naturally existing compound.

\section{References}

1. Santana SS, Gennari-Cardoso ML, Carvalho FC, RoqueBarreira MC, Santiago AS, Alvim FC and Pirovani CP: Eutirucallin, a RIP-2 type lectin from the latex of Euphorbia tirucalli L. presents proinflammatory properties. PLoS One 9: e88422, 2014.

2. Girbes T, Ferreras JM, Arias FJ, Muñoz R, Iglesias R, Jimenez P, Rojo MA, Arias Y, Perez Y, Benitez J, et al: Non-toxic type 2 ribosome-inactivating proteins (RIPs) from Sambucus: Occurrence, cellular and molecular activities and potential uses. Cell Mol Biol (Noisy-le-grand) 49: 537-545, 2003.

3. He WJ and Liu WY: Cinnamomin: A multifunctional type II ribosome-inactivating protein. Int $\mathbf{J}$ Biochem Cell Biol 35 1021-1027, 2003.

4. Stirpe F: Ribosome-inactivating proteins. Toxicon 44: 371-383, 2004.

5. Walsh MJ, Dodd JE and Hautbergue GM: Ribosome-inactivating proteins: Potent poisons and molecular tools. Virulence 4 : 774-784, 2013.

6. Hartley MR and Lord JM: Cytotoxic ribosome-inactivating lectins from plants. Biochim Biophys Acta 1701: 1-14, 2004.

7. Stirpe F and Battelli MG: Ribosome-inactivating proteins: Progress and problems. Cell Mol Life Sci 63: 1850-1866, 2006.

8. Peumans WJ, Hao Q and Van Damme EJ: Ribosome-inactivating proteins from plants: more than RNA N-glycosidases? FASEB J 15: 1493-1506, 2001

9. Fong WP, Mock WY and Ng TB: Intrinsic ribonuclease activities in ribonuclease and ribosome-inactivating proteins from the seeds of bitter gourd. Int J Biochem Cell Biol 32: 571-577, 2000.

10. Horrix C, Raviv Z, Flescher E, Voss C and Berger MR: Plant ribosome-inactivating proteins type II induce the unfolded protein response in human cancer cells. Cell Mol Life Sci 68: 1269-1281, 2011

11. de Virgilio M, Lombardi A, Caliandro R and Fabbrini MS: Ribosome-inactivating proteins: From plant defense to tumor attack. Toxins (Basel) 2: 2699-2737, 2010.

12. Nielsen K and Boston RS: Ribosome-inactivating proteins: A plant perspective. Annu Rev Plant Physiol Plant Mol Biol 52: 785-816, 2001.

13. Massa S, Paolini F, Spanò L, Franconi R and Venuti A: Mutants of plant genes for developing cancer vaccines. Hum Vaccin 7 (Suppl): 147-155, 2011.

14. Zarovni N, Vago R and Fabbrini MS: Saporin suicide gene therapy. Methods Mol Biol 542: 261-283, 2009.

15. Preijers FW: Rationale for the clinical use of immunotoxins: Monoclonal antibodies conjugated to ribosome-inactivating proteins. Leuk Lymphoma 9: 293-304, 1993.

16. Voss C, Eyol E and Berger MR: Identification of potent anticancer activity in Ximenia americana aqueous extracts used by African traditional medicine. Toxicol Appl Pharmacol 211: 177-187, 2006.
17. Voss C, Eyol E, Frank M, von der Lieth $\mathrm{CW}$ and Berger MR: Identification and characterization of riproximin, a new type II ribosome-inactivating protein with antineoplastic activity from Ximenia americana. FASEB J 20: 1194-1196, 2006.

18. Bayer H, Ey N, Wattenberg A, Voss C and Berger MR: Purification and characterization of riproximin from Ximenia americana fruit kernels. Protein Expr Purif 82: 97-105, 2012.

19. Bayer H, Essig K, Stanzel S, Frank M, Gildersleeve JC, Berger MR and Voss C: Evaluation of riproximin binding properties reveals a novel mechanism for cellular targeting. J Biol Chem 287: 35873-35886, 2012.

20. Adwan H, Bayer H, Pervaiz A, Sagini M and Berger MR: Riproximin is a recently discovered type II ribosome inactivating protein with potential for treating cancer. Biotechnol Adv 32: 1077-1090, 2014 .

21. Adwan H, Murtaja A, Kadhim Al-Taee K, Pervaiz A, Hielscher T and Berger MR: Riproximin's activity depends on gene expression and sensitizes PDAC cells to TRAIL. Cancer Biol Ther 15: 1185-1197, 2014

22. Livak KJ and Schmittgen TD: Analysis of relative gene expression data using real-time quantitative PCR and the 2(-Delta Delta C(T)) method. Methods 25: 402-408, 2001.

23. Kodama T, Doukas AG and Hamblin MR: Delivery of ribosomeinactivating protein toxin into cancer cells with shock waves. Cancer Lett 189: 69-75, 2003

24. Gasperi-Campani A, Musa AR and Roncuzzi L: Diverse activity of sc-RIP saporin 6 on primary and metastatic melanoma cells in vitro. Melanoma Res 3: 363-367, 1993.

25. Wang C, Yang A, Zhang B, Yin Q, Huang H, Chen M and Xie J: PANC-1 pancreatic cancer cell growth inhibited by cucurmosin alone and in combination with an epidermal growth factor receptor-targeted drug. Pancreas 43: 291-297, 2014.

26. Podlech O, Harter PN, Mittelbronn M, Poschel S and Naumann U: Fermented mistletoe extract as a multimodal antitumoral agent in gliomas. eCAM 2012: 501796, 2012.

27. Mohamed MS, Veeranarayanan S, Poulose AC, Nagaoka Y, Minegishi H, Yoshida Y, Maekawa T and Kumar DS: Type 1 ribotoxin-curcin conjugated biogenic gold nanoparticles for a multimodal therapeutic approach towards brain cancer. Biochim Biophys Acta 1840: 1657-1669, 2014

28. Wei F, Cao S, Ren X, Liu H, Yu J, Li H and Hao X: Efficient antiproliferative and antiangiogenic effects on human ovarian cancer growth by gene transfer of attenuated mutants of Shigalike toxin I. Int J Gynecol Cancer 18: 677-691, 2008.

29. Fan X, He L, Meng Y, Li G, Li L and Meng Y: A-MMC and MAP30, two ribosome-inactivating proteins extracted from Momordica charantia, induce cell cycle arrest and apoptosis in A549 human lung carcinoma cells. Mol Med Rep 11: 3553-3558, 2015.

30. Fang EF, Zhang CZ, Ng TB, Wong JH, Pan WL, Ye XJ, Chan YS and Fong WP: Momordica charantia lectin, a type II ribosome inactivating protein, exhibits antitumor activity toward human nasopharyngeal carcinoma cells in vitro and in vivo. Cancer Prev Res (Phila) 5: 109-121, 2012.

31. Narayanan S, Surendranath K, Bora N, Surolia A and Karande AA: Ribosome inactivating proteins and apoptosis. FEBS Lett 579: 1324-1331, 2005.

32. Gan YH, Peng SQ and Liu HY: Molecular mechanism of apoptosis induced by ricin in HeLa cells. Acta Pharmacol Sin 21: 243-248, 2000.

33. Garrosa M, Jiménez P, Tejero J, Cabrero P, Cordoba-Diaz D, Quinto EJ, Gayoso MJ and Girbés T: Toxicity of the antiribosomal Lectin Ebulin $\mathrm{f}$ in lungs and intestines in elderly mice. Toxins (Basel) 7: 367-379, 2015.

34. Zhang D, Chen B, Zhou J, Zhou L, Li Q, Liu F, Chou KY, Tao L and Lu LM: Low concentrations of trichosanthin induce apoptosis and cell cycle arrest via c-Jun N-terminal protein kinase/mitogen-activated protein kinase activation. Mol Med Rep 11: 349-356, 2015.

35. Grimm S and Noteborn M: Anticancer genes: Inducers of tumour-specific cell death signalling. Trends Mol Med 16: 88-96, 2010.

36. Tian H, Wang J, Zhang B, Di J, Chen F, Li H, Li L, Pei D and Zheng J: MDA-7/IL-24 induces Bcl-2 denitrosylation and ubiquitin-degradation involved in cancer cell apoptosis. PLoS One 7: e37200, 2012.

37. Dalloul A and Sainz-Perez A: Interleukin-24: A molecule with potential anti-cancer activity and a cytokine in search of a function. Endocr Metab Immune Disord Drug Targets 9: 353-360, 2009. 
38. Emdad L, Lebedeva IV, Su ZZ, Gupta P, Sauane M, Dash R, Grant S, Dent P, Curiel DT, Sarkar D, et al: Historical perspective and recent insights into our understanding of the molecular and biochemical basis of the antitumor properties of mda-7/IL-24. Cancer Biol Ther 8: 391-400, 2009.

39. Gupta P, Su ZZ, Lebedeva IV, Sarkar D, Sauane M, Emdad L, Bachelor MA, Grant S, Curiel DT and Dent P: mda-7/IL-24: Multifunctional cancer-specific apoptosis-inducing cytokine. Pharmacol Ther 111: 596-628, 2006.

40. Choi Y, Roh MS, Hong YS, Lee HS and Hur WJ: Interleukin-24 is correlated with differentiation and lymph node numbers in rectal cancer. World J Gastroenterol 17: 1167-1173, 2011.

41. Ellerhorst JA, Prieto VG, Ekmekcioglu S, Broemeling L, Yekell S, Chada S and Grimm EA: Loss of MDA-7 expression with progression of melanoma. J Clin Oncol 20: 1069-1074, 2002.

42. Patani N, Douglas-Jones A, Mansel R, Jiang W and Mokbel K: Tumour suppressor function of MDA-7/IL-24 in human breast cancer. Cancer Cell Int 10: 29, 2010.

43. Xu S, Oshima T, Imada T, Masuda M, Debnath B, Grande F, Garofalo A and Neamati N: Stabilization of MDA-7/IL-24 for colon cancer therapy. Cancer Lett 335: 421-430, 2013.
44. Whitaker EL,Filippov VA and Duerksen-Hughes PJ: Interleukin 24: Mechanisms and therapeutic potential of an anti-cancer gene. Cytokine Growth Factor Rev 23: 323-331, 2012.

45. Sarkar D, Su ZZ, Lebedeva IV, Sauane M, Gopalkrishnan RV, Valerie K, Dent P and Fisher PB: mda-7 (IL-24) mediates selective apoptosis in human melanoma cells by inducing the coordinated overexpression of the GADD family of genes by means of p38 MAPK. Proc Natl Acad Sci USA 99: 10054-10059, 2002.

46. Cretu A, Sha X, Tront J, Hoffman B and Liebermann DA: Stress sensor Gadd45 genes as therapeutic targets in cancer. Cancer Ther 7A: 268-276, 2009.

47. McCullough KD, Martindale JL, Klotz LO, Aw TY and Holbrook NJ: Gadd153 sensitizes cells to endoplasmic reticulum stress by down-regulating $\mathrm{Bcl} 2$ and perturbing the cellular redox state. Mol Cell Biol 21: 1249-1259, 2001.

48. Hollander MC, Sheikh MS, Yu K, Zhan Q, Iglesias M, Woodworth C and Fornace AJ Jr: Activation of Gadd34 by diverse apoptotic signals and suppression of its growth inhibitory effects by apoptotic inhibitors. Int J Cancer 96: 22-31, 2001. 